Интернет-журнал «Отходы и ресурсы» https://resources.today

Russian Journal of Resources, Conservation and Recycling

2019, №3, Том 6 / 2019, No 3, Vol 6 https://resources.today/issue-3-2019.html

URL статьи: https://resources.today/PDF/16ECOR319.pdf

DOI: 10.15862/16ECOR319 (http://dx.doi.org/10.15862/16ECOR319)

Ссылка для цитирования этой статьи:

Сплендер В.А., Орлов А.В. Комплексная оценка уровня инвестиционной привлекательности стартапа // Интернет-журнал «Отходы и ресурсы», 2019 №3, https://resources.today/PDF/16ECOR319.pdf (доступ свободный). Загл. с экрана. Яз. рус., англ. DOI: 10.15862/16ECOR319

For citation:

Splender V.A., Orlov A.V. (2019). A comprehensive assessment of the investment attractiveness of a startup. Russian Journal of Resources, Conservation and Recycling, [online] 3(6). Available at:

https://resources.today/PDF/16ECOR319.pdf (in Russian) DOI: 10.15862/16ECOR319

\title{
УДК 339.1
}

\section{ГРНТИ 06.71.09}

\section{Сплендер Виктор Анатольевич}

ФГКВОУ ВО «Военный университет» Министерства обороны Российской Федерации, Москва, Россия Профессор

Доктор военных наук, доцент

E-mail: sva-777@mail.ru

РИНЦ: http://elibrary.ru/author_profile.asp?id=534094

Орлов Александр Владимирович

ФГКОУ ВО «Московский университет министерства внутренних дел

Российской Федерации имени В.Я. Кикотя», Москва, Россия

Старший преподаватель кафедры «Экономической безопасности, финансов и экономического анализа»

Кандидат экономических наук, доцент

E-mail: alexandr_orlof@mail.ru

\section{Комплексная оценка уровня инвестиционной привлекательности стартапа}

Аннотация. В статье рассматривается методика комплексной оценки инвестиционной привлекательности стартап-проекта и критерии его эффективности. Инвестиционная привлекательность стартапа - это такая экономическая категория, которая представляет собой комплексный показатель объективных и субъективных характеристик стартапа, характеризующийся эффективностью использования имущества предприятия, его платежеспособностью, финансовой устойчивостью, способностью к саморазвитию на базе повышения доходности капитала, качества и конкурентоспособности продукции, и отражающий целесообразность инвестирования средств. Для выбора оптимальных критериев инвестиционной привлекательности стартапа и выработки необходимых процедур их использования в первой части статьи рассмотрены проблемы в деятельности предприятий, которые могут оказывать влияние на их инвестиционную привлекательность. По отношению к выделенным составляющим определяются критерии оценки их состояния и степень влияния на инвестиционную привлекательность. При отборе стартап-проекта авторы предложили ряд важнейших критериев, из которых выделили не менее 6. Их наличие и достаточность являются необходимыми условиями для предполагаемой его реализации. Далее авторами предлагается единая методика комплексной оценки уровня инвестиционной привлекательности стартапа. Наличие и владение такой методикой позволит руководителю восполнить недостаток опыта 
внедрения стартап-проектов и разработки новых инновационных идей, так как многие, попадая в форс-мажорные обстоятельства испытывают растерянность и панику, что зачастую ведёт к значительным финансовым потерям. Для этого в структуре предполагаемого бизнес-стартапа предварительно выделяется ряд элементов, имеющих наибольшее влияние на инвестиционные характеристики. Таким образом, данное исследование помогает потенциальным инвесторам финансовых средств в новые стартап-проекты при применении разработанной методики их оценки провести заблаговременно прогнозирование и избежать основных проблем, возникающих перед ними.

Ключевые слова: стартап; проект; критерий; методика; инвестиции; инвестор; финансовая устойчивость; характеристики

Инвестиционная привлекательность стартапа - это экономическая категория, которая представляет собой комплексный показатель объективных и субъективных характеристик стартапа, характеризующийся эффективностью использования имущества предприятия, его платежеспособностью, финансовой устойчивостью, способностью к саморазвитию на базе повышения доходности капитала, качества и конкурентоспособности продукции, и отражающий целесообразность инвестирования средств [1].

Для руководителя и команды стартапа оценка инвестиционной привлекательности определяет возможность его успешной реализации в текущих условиях, помогает оценить его сильные и слабые стороны, указывает на пути улучшения модели работы стартапа.

В целях выбора оптимальных критериев инвестиционной привлекательности стартапа и выработки необходимых процедур их использования необходимо заранее рассмотреть проблемы в деятельности отечественных предприятий, которые могут оказывать влияние на их инвестиционную привлекательность:

- $\quad$ Российские инвесторы неохотно вкладывают финансовые средства на начальных этапах формирования идеи стартапа. Это связано с тем, что они заинтересованы в поддержке уже действующих компаний, расширяющих свой бизнес и находящихся в поиске финансовых средств под эти цели. В этих условиях мы считаем, что необходимо проведение конкурсного отбора инновационных идей и инновационных проектов ещё на стадиях их формирования.

- $\quad$ Многие стартапы, находясь на этапе создания, в перспективе оказываются не прибыльными, из-за отсутствия четкого обоснования ключевых характеристик и бизнес-плана. В большинстве своём это связано с тем, что стартапер хочет побыстрее реализовать свою бизнес-идею пока кто-нибудь другой не воплотил ее в жизнь. Таким образом им предполагается, что сама идея - это уже залог успеха. Однако оказывается, что впереди много проблем в её реализации.

Предреализационный этап стартапов неэффективно поддерживается инвесторами. На основании данных российской статистики, только за 2017-2018 гг. некоммерческие и инфраструктурные организации инвестировали около 20 млн долл. в 60 отечественные стартапы. Однако как таковой отбор эффективных стартапов практически отсутствует в связи с небольшим количеством претендентов - стартаперов в результате чего зачастую финансируются низкокачественные стартап-проекты.

- Взаимодействие инвесторов со стартаперами зачастую организованно не эффективно. Стартаперы, в большинстве своем, считают, что бизнес-инвесторы осознают, куда инвестируют финансовые средства и могут спрогнозировать ориентировочную доходность и прибыльность стартапа. Инвесторы, в свою очередь, также думают, что стартапер всё держит «под контролем», а им достаточно предоставить деньги под какой-нибудь проект и в дальнейшем просто получать гарантированную прибыль. Однако результат зачастую не 
соответствует ожиданиям. Оказываемое давление со стороны разочаровавшегося инвестора на стартапера заставляет последнего нервничать и, тем самым, совершать ряд непоправимых ошибок, влекущих финансовые потери, а в худшем случае и крах предприятия.

- Инвесторы на стадии внедрения стартап-проекта ведут агрессивную политику забирая 30-80\% бизнеса. При этом активно ущемляются интересы самих стартаперов разработавших данную бизнес-идею. Инвестируемых средств чаще всего хватает на короткий период времени - до одного года и на следующем этапе реализации стартапа нового инвестора быстро привлечь бывает чрезвычайно сложно, так заслуга основателей проекта в его развитии становится не явная. Первоначальные инвесторы в свою очередь предполагают, что в недостаточной заинтересованности бизнеса в стартап-проекте виновны сами основатели стартапа, низкое качество их компетенций и как следствие не проработанность проекта.

- $\quad$ Недостаточный опыт внедрения стартап-проектов и разработки инновационных идей приводит к тому, что многие стартаперы, попадая в форс-мажорные обстоятельства испытывают растерянность и панику, что так же зачастую ведёт к финансовым потерям.

В целях решения вышеуказанных проблем нами предлагается методика комплексной оценки уровня инвестиционной привлекательности стартапа. Для этого в структуре предполагаемого бизнес-стартапа необходимо предварительно выделить ряд его элементов, имеющих наибольшее влияние на инновационные и инвестиционные характеристики. А уже по отношению к выделенным составляющим определиться с критериями оценки их состояния и влияния на уровень инвестиционной привлекательности $[4 ; 6]$.

По нашему мнению, такими критериями должны стать (таблица 1).

Таблица 1

Основные критерии оценки стартап-проекта и их содержание [2]

\begin{tabular}{|c|c|c|c|}
\hline № & Название критерия & $\begin{array}{c}\text { Вес } \\
\text { критерия } \\
\text { Рх }\end{array}$ & $\begin{array}{c}\text { Значение } \\
\text { критерия Xn } \\
\text { i (диапазон) }\end{array}$ \\
\hline 1 & 2 & 3 & 4 \\
\hline \multicolumn{4}{|c|}{ а) оригинальность проекта: } \\
\hline 1 & $\begin{array}{l}\text { Масштаб оригинальности (глобальный, отраслевой, территориальный, } \\
\text { частный уровень, масштаб не определен) }\end{array}$ & 6 & $0-10$ \\
\hline \multirow[t]{2}{*}{2} & $\begin{array}{l}\text { Степень оригинальности (радикальный, комбинаторный } \\
\text { модифицирующий характер, проект неоригинален) }\end{array}$ & 7 & $0-10$ \\
\hline & Итоговая (усредненная) оценка & & $0-10$ \\
\hline \multicolumn{4}{|c|}{ б) новизна проекта: } \\
\hline \multirow[t]{2}{*}{3} & $\begin{array}{l}\text { Уровень подтверждения новизны (высокий, средний, низкий, } \\
\text { подтверждение отсутствует) }\end{array}$ & 9 & $0-10$ \\
\hline & Итоговая оценка & & $0-10$ \\
\hline \multicolumn{4}{|c|}{ в) проработанность проекта: } \\
\hline 4 & $\begin{array}{l}\text { Степень проработанности (полная проработанность, достаточная, } \\
\text { недостаточная проработанность, проект непроработан) }\end{array}$ & 9 & $0-10$ \\
\hline \multirow[t]{2}{*}{5} & $\begin{array}{l}\text { Уровень комплексности (высокий, средний, низкий, учет факторов не } \\
\text { осуществлялся) }\end{array}$ & 8 & $0-10$ \\
\hline & Итоговая (усредненная) оценка & & $0-10$ \\
\hline \multicolumn{4}{|c|}{ г) потенциальная эффективность: } \\
\hline \multirow[t]{2}{*}{6} & $\begin{array}{l}\text { Уровень эффективности (высокий, средний, низкий, проект } \\
\text { неэффективен) }\end{array}$ & 10 & $0-10$ \\
\hline & Итоговая оценка & & $0-10$ \\
\hline \multicolumn{4}{|c|}{ д) ресурсное обеспечение проекта: } \\
\hline 7 & $\begin{array}{l}\text { Уровень потребности в специальной подготовке (низкий, средний, } \\
\text { высокий, оценка проекта затруднена) }\end{array}$ & 8 & $0-10$ \\
\hline 8 & $\begin{array}{l}\text { Уровень ресурсного обеспечения (высокий, средний, низкий, оценка } \\
\text { ресурсной обеспеченности не проводилась) }\end{array}$ & 8 & $0-10$ \\
\hline
\end{tabular}




\begin{tabular}{|c|c|c|c|}
\hline № & Название критерия & $\begin{array}{l}\text { Вес } \\
\text { критерия } \\
\text { Рx }\end{array}$ & $\begin{array}{l}\text { Значение } \\
\text { критерия Xn } \\
\text { i (диапазон) }\end{array}$ \\
\hline \multirow[t]{2}{*}{1} & 2 & 3 & 4 \\
\hline & Итоговая (усредненная) оценка & & $0-10$ \\
\hline \multicolumn{4}{|c|}{ е) коммерциализируемость проекта: } \\
\hline 9 & $\begin{array}{l}\text { Масштаб коммерциализируемости (полностью коммерциализуем, в } \\
\text { значительной степени коммерциализуем, может быть коммерциализуем, } \\
\text { проект не коммерциализуем) }\end{array}$ & 9 & $0-10$ \\
\hline & Итоговая оценка & & $0-10$ \\
\hline
\end{tabular}

1. Оригинальность стартап-проекта.

Оригинальность - качество стартапа, выражающееся в его неповторимости, своеобразии и нестандартности. Эти качества делают его привлекательным в глазах потенциальных инвесторов.

При оценке оригинальности стартап-проекта инвестор будет ориентироваться, во-первых, на степень оригинальности - насколько проект или идея являются новыми, вовторых, на то, в каких масштабах проект оригинален.

Чем масштабнее оригинальность и выше ее степень, тем выше комплексная оценка стартапа.

\section{2. Новизна проекта.}

Это одна из основных характеристик стартапа. Новизна проявляется в расширении поля исследования проблемы. Новизна в отличие от оригинальности предполагает патентную чистоту, лицензионную защиту, приоритетность направления инноваций, конкурентоспособность внедряемого новшества.

Стартап-проект обладает новизной, если:

- $\quad$ обуславливает новые процессы, концепции, способы и материалы;

- $\quad$ раскрывает особые качества, свойства, принципы работы.

При анализе уровня новизны проекта следует выяснить, чем подтверждается новизна (авторские права, патентные права, ноу-хау, товарный знак, свидетельства, доменное имя), и дать ему оценку [7; 10].

\section{3. Проработанность стартап-проекта.}

Проработанность стартап-проекта - обоснование стратегических и тактических целей и описание механизма их достижения с учётом факторов риска, результатов маркетинговых исследований и др.

Оценка проработанности проекта производится по двум параметрам: уровню проработанности и степени комплексности.

Стартап-проект является проработанным, если реализует комплексный подход в решении проблем, объединяя множество элементов в одну систему, с учетом многообразия факторов - технических, экономических, информационных, экологических, социальных и культурных.

Проработанный проект характеризуется высоким уровнем разработанности при наличии четкого плана развития, имеется перечень потенциально возможных рисков, осуществлен их прогноз, а также проработаны варианты способов их преодоления.

\section{4. Эффективность реализации стартап-проекта.}

Под эффективностью в общем случае понимают соответствие полученных от проекта результатов - как экономических (в частности, прибыли), так и внеэкономических (снятие социальной напряженности в регионе) - и затрат на проект. Эффективность инновационного проекта - это категория, отражающая соответствие проекта целям и интересам участников 
проекта, под которыми понимаются субъекты инвестиционной деятельности (рассмотрены выше) и общество в целом.

Среди сложившихся в мировой практике основных принципов и подходов, к оценке эффективности проектов, можно выделить следующие:

- $\quad$ моделирование потоков товаров, ресурсов и финансовых средств;

- у учет результатов анализа рынка, финансового состояния предприятия, претендующего на реализацию проекта, степени доверия к руководителям проекта, влияния реализации проекта на окружающую природную среду и т. д.;

- $\quad$ оценка экономического эффекта через сопоставление перспективных результатов и издержек с ориентацией на достижение требуемой нормы дохода на капитал и иных критериев;

- приведение будущих разновременных расходов и доходов к условиям их соизмеримости по экономической ценности в начальном периоде;

- $\quad$ учет влияния инфляции, задержек платежей и других факторов на ценность используемых денежных средств;

- $\quad$ учет неопределенности и рисков, связанных с осуществлением проекта.

Требуется проводить оценку следующих видов эффективности:

1. эффективность стартап-проекта в целом;

2. эффективность участия в стартап-проекте.

Эффективность стартап-проекта в целом. Данную оценку проводят для того, чтобы определить потенциальную привлекательность проекта, целесообразность его принятия для потенциальных участников. Она показывает объективную приемлемость стартап-проекта вне зависимости от финансовых возможностей его участников. Данная эффективность, в свою очередь, включает в себя:

- общественную (социально-экономическую) эффективность стартап-проекта;

- $\quad$ коммерческую эффективность стартап-проекта.

Общественная эффективность учитывает социально-экономические последствия реализации инвестиционного стартап-проекта для общества в целом, в том числе как непосредственные затраты на проект и результаты от проекта, так и внешние эффекты социальные, политические и иные эффекты.

Коммерческая эффективность инвестиционного стартап-проекта раскрывает финансовые перспективы его осуществления для участника стартап-проекта, если предположить, что он самостоятельно производит все необходимые затраты на проект и пользуется всеми его результатами. Следовательно, при оценке коммерческой эффективности необходимо абстрагироваться от возможностей участников проекта по финансированию затрат на стартап-проект, условно предполагая, что необходимые средства имеются.

Эффективность участия в проекте. Она определяется в соответствии с целью проверки финансовой реализуемости проекта и заинтересованности в нем всех его участников. Данная эффективность включает $[3 ; 5 ; 10]$ :

• пективность участия предприятий в проекте;

- $\quad$ эффективность инвестирования в акции предприятия;

- $\quad$ эффективность участия в проекте структур более высокого уровня по отношению к предприятиям - участникам стартап-проекта (народнохозяйственная, региональная, отраслевая и другие эффективности); 
- $\quad$ бюджетная эффективность стартап-проекта (эффективность участия государства в проекте с точки зрения расходов и доходов бюджетов всех уровней).

На этом этапе оценки необходимо учитывать, насколько проект в случае успешной реализации способен обеспечить:

- $\quad$ повышения эффективности процесса производства продукции и услуг;

- $\quad$ комфорт и высокое качество жизни;

- $\quad$ расширение возможностей, предоставляемых новыми рынками;

- $\quad$ эффективность управления системами, производством, финансами, персоналом и Т. д.

5. Ресурсное обеспечение проекта.

Критерием отбора стартап-проекта выступает наличие и достаточность заявленных инициатором проекта ресурсов в регионе для предполагаемой его реализации. Следует различать условия реализации стартап-проекта и ресурсную обеспеченность.

Инвестиционная привлекательность определяется, в первую очередь, наличием ресурсов для создания продукта или услуги. В случае их отсутствия могут возникать угрозы эффективной реализации проекта. Заявленная потребность в ресурсах должна быть обоснована, указано наличие какого ресурсного потенциала необходимо для реализации проекта (финансового, материально-технического, трудового, информационного, энергетического и экономического).

Условия реализации стартап-проекта - это совокупность требований на проектирование и производство отдельных продуктов и услуг [7].

\section{6. Коммерииализуемость стартап-проекта.}

Коммерциализация инноваций - это привлечение инвесторов для финансирования деятельности по реализации этого новшества из расчета участия в будущей прибыли в случае успеха. В тоже время процесс выведения стартап-проекта на рынок является ключевым этапом инновационной деятельности после чего (выведения на рынок) происходит возмещение затрат разработчика (или владельца) инновационного продукта и получение им прибыли от своей деятельности [6].

При оценке коммерциализированности требуется оценить коммерческий потенциал и уровень готовности к реализации. Так как, уровень готовности стартап-проекта оценивается в рамках такого критерия как его проработанность, следовательно ключевой оценке необходимо подвергнуть его коммерческий потенциал.

При оценке уровня коммерциализуемости проекта оценивается, в каких масштабах (страна, регион, организация) и секторах экономики может быть коммерциализирован проект.

Особое значение имеет наличие коммерческой, бюджетной эффективности, представлена или нет финансовая бизнес-модель, обоснованы источники финансирования, раскрыты направления формирования доходов и определен период окупаемости затрат и т. д. [7-9].

Итоговые балльные оценки предпочтительности заявленных проектов должны отражать степень соответствия этих проектов предъявляемым требованиям, а каждая «частная» оценка соответствие заявки соответствующему частному требованию, что позволит повысить вероятность правильного определения новизны, перспективности и объективной целесообразности развития заявленного проекта.

Таким образом, в основе принятия решения инвестором о том, в какой стартап инвестировать средства наиболее рациональным способом, лежит тщательный анализ объекта инвестирования. Такие решения, исходя из деловой и инвестиционной практики, принимаются 
на базе вполне конкретных показателей соответствия критериям, оставляя на втором месте чисто субъективные желания инвестора в категориях компетенции или просто персональных предпочтений.

\section{ЛИТЕРАТУРА}

1. Инвестиционная привлекательность стартапа и её особенности / Статья [Электронный ресурс] Интернет-ресурс FOYKES URL: http://foykes.com/investitsionnaya-privlekatelnost-startapa-i-eyo-osobennosti/ (дата обращения: 17.10.19).

2. Факторы, определяющие инвестиционную привлекательность стартапа для инвестора, на макро- и микроуровне / Статья [Электронный ресурс] Pandia URL: https://pandia.ru/text/82/353/60724-10.php (дата обращения: 17.10.19).

3. Методические основы оценки эффективности инвестиционных проектов / Статья [Электронный ресурс] Интернет-ресурс Studbooks.net URL: https://studbooks.net/1659310/finansy/metodicheskie_osnovy_otsenki_effektivnosti_i nvestitsionnyh_proektov (дата обращения: 17.10.19).

4. Антонюк О.А., Бутов А.Г. Повышение качества деятельности предприятия на основе формирования алгоритма управления его экономическим потенциалом / Статья [Электронный ресурс] Институциональные механизмы развития управленческой деятельности // Материалы III Международной научнопрактической конференции. 2017 Изд-во: Московский институт экономики, политики и права г. Москва URL: https://elibrary.ru/item.asp?id=32634971 (дата обращения 12.08.2019).

5. Карпов А.С., Сплендер В.А. Особенности формирования конкурентных преимуществ организаций наукоемких отраслей // Вестник Московского гуманитарно-экономического института. 2015. № 4. С. 16.

6. Полухин И.В. Необходимость и сущность коммерциализации инноваций предприятий ракетно-космической промышленности // Менеджмент социальных и экономических систем. $2016 . \quad$ №3. https://cyberleninka.ru/article/n/neobhodimost-i-suschnost-kommertsializatsiiinnovatsiy-predpriyatiy-raketno-kosmicheskoy-promyshlennosti (дата обращения: 17.10.2019).

7. Сплендер В.А., Гребеник Т.В. Инновационные механизмы кредитования субъектов малого и среднего предпринимательства // В сборнике: Научные труды преподавателей МАЭП Московская академия экономики и права. Москва, 2014. С. 33-39.

8. Долбилов А.В. Облачная платформа в условиях сетевой атаки / Статья [Электронный ресурс] Телекоммуникационные и вычислительные системы 2017 // Труды международной научно-технической конференции. 2017. Изд-во: «Горячая линия - Телеком» URL: https://elibrary.ru/item.asp?id=30673177 (дата обращения 12.08.2019).

9. Лошаков А.С. Новые подходы к повышению производительности труда в современной России / Статья [Электронный ресурс] Государственный аудит: экономика, управление и право Москва, 2016 Изд-во: Высшая школа гос. аудита МГУ URL: https://elibrary.ru/item.asp?id=28312805 (дата обращения 12.08.2019).

10. Самаруха А.В. Актуальные проблемы развития финансирования технологического предпринимательства в России // Региональная Россия: история и современность. 2018. № 1. С. 235-239. 
Splender Viktor Anatol'evich

Military university of the ministry of defense of Russia, Moscow, Russia

E-mail: sva-777@mail.ru

\title{
Orlov Alexandr Viktorovich
}

Moscow university of the ministry of internal affairs of the Russian Federation named after V.Ya. Kikotya, Moscow, Russia E-mail: alexandr_orlof@mail.ru

\section{A comprehensive assessment of the investment attractiveness of a startup}

\begin{abstract}
The article deals with the method of comprehensive assessment of the investment attractiveness of a startup project and the criteria for its effectiveness. Investment attractiveness of a startup is such an economic category, which is a complex indicator of objective and subjective characteristics of a startup, characterized by the efficiency of using the property of the enterprise, its solvency, financial stability, the ability to self-development on the basis of increasing the return on capital, quality and competitiveness of products, and reflecting the feasibility of investing funds. To select the optimal criteria for the investment attractiveness of a startup and develop the necessary procedures for their use, the first part of the article considers the problems in the activities of enterprises that can affect their investment attractiveness. In relation to the selected components, the criteria for assessing their condition and the degree of influence on investment attractiveness are determined. When selecting a startup project, the authors proposed a number of important criteria, of which at least 6 were singled out. Their availability and sufficiency are necessary conditions for its intended implementation. Further, the authors propose a single method of comprehensive assessment of the level of investment attractiveness of a startup. The presence and possession of such a technique will allow the head to make up for the lack of experience in the implementation of startup projects and the development of new innovative ideas, as many, falling into force majeure experience confusion and panic, which often leads to significant financial losses. To do this, a number of elements that have the greatest impact on investment characteristics are pre-allocated in the structure of the proposed business startup. Thus, this study helps potential investors of financial resources in new start-up projects to carry out forecasting in advance and avoid the main problems that arise in front of them when applying the developed methodology of their assessment.
\end{abstract}

Keywords: startup; project; criterion; methodology; investment; investor; financial stability; characteristics

\section{REFERENCES}

1. FOYKES. (n.d.). Startup investment attractiveness and its features. [online] Available at: http://foykes.com/investitsionnaya-privlekatelnost-startapa-i-eyo-osobennosti/ (in Russian) [Accessed 17.10.19].

2. Pandia. (n.d.). Factors determining the investment attractiveness of a startup for an investor, at the macro and micro levels. [online] Available at: https://pandia.ru/text/82/353/60724-10.php (in Russian) [Accessed 17.10.19].

3. Studbooks.net. (n.d.). Methodological basis for evaluating the effectiveness of investment projects. [online] Available at: https://studbooks.net/1659310/finansy/metodicheskie_osnovy_otsenki_effektivnosti_i nvestitsionnyh_proektov (in Russian) [Accessed 17.10.19]. 
4. Antonyuk O.A., Butov A.G. (2017). Povyshenie kachestva deyatel'nosti predpriyatiya na osnove formirovaniya algoritma upravleniya ego ehkonomicheskim potentsialom. [Improving the quality of the enterprise based on the formation of an algorithm for managing its economic potential.] Moscow: Moscow Institute of Economics, Politics and Law, [online] Available at: https://elibrary.ru/item.asp?id=32634971 [Accessed 12.08.2019].

5. Karpov A.S., Splender V.A. (2015). Features of the formation of competitive advantages of organizations of high-tech industries. Bulletin of the Moscow Humanitarian-Economic Institute, 4, p. 16 (in Russian).

6. Polukhin I.V. (2016). The need and essence of the commercialization of innovations in the space industry. Management of social and economic systems, [online] 3. Available at: $\quad$ https://cyberleninka.ru/article/n/neobhodimost-i-suschnost-kommertsializatsiiinnovatsiy-predpriyatiy-raketno-kosmicheskoy-promyshlennosti (in Russian) [Accessed 17.10.2019].

7. Splender V.A., Grebenik T.V. (2014). Innovatsionnye mekhanizmy kreditovaniya sub"ektov malogo i srednego predprinimatel'stva. [Innovative lending mechanisms for small and medium-sized enterprises.] Moscow: Moscow Academy of Economics and Law, pp. 33-39.

8. Dolbilov A.V. (2017). Oblachnaya platforma v usloviyakh setevoy ataki. [Network Attack Cloud Platform.] Moscow: Publishing House "Hot Line - Telecom", [online] Available at: https://elibrary.ru/item.asp?id=30673177 [Accessed 12.08.2019].

9. Loshakov A.S. (2016). Novye podkhody k povysheniyu proizvoditel'nosti truda v sovremennoy Rossii. [New approaches to increasing labor productivity in modern Russia.] Moscow: Graduate School of State Audit Moscow State University, [online] Available at: https://elibrary.ru/item.asp?id=28312805 [Accessed 12.08.2019].

10. Samarukha A.V. (2018). Actual problems of financing the development of technological entrepreneurship in Russia. Regional Russia: history and modernity, 1, pp. 235-239 (in Russian). 